\title{
Travel Time Modeling and Simulation of a Mobile Racks Automated Storage/Retrieval System
}

\author{
Amine Hakim Guezzen, Zaki Sari, Pierre Castagna, and Olivier Cardin
}

\begin{abstract}
AS/RS systems are devices designed for automated storage and retrieval of parts and items in manufacturing, distribution, retail, wholesale and institutions. This paper consists in studying a storage system with Mobil racks (M-AS/RS) which are a variation of the multi aisles AS/RS. This mobile storage system is composed of racks moving laterally on rails so that one can open an aisle between any two adjacent racks, it makes it possible to optimize the use of space; the characteristic of these systems is that the aisles of service appear only when one operation of storage or retrieval is envisaged in the corresponding racks.

One of the most important criteria of performances of these systems is the average cycle time of the storage/Retrieval machine.

In this paper our interest is concerned with the mathematical modeling of M-AS/RS system. We presented a closed form analytical expression allowing an approximate calculation of the travel time of a Mobil Racks-AS/RS. This expression was compared with simulation results and an exact discrete expression developed earlier by one of the authors.
\end{abstract}

Index Terms-M-AS/RS, Mobil racks automated storage/retrieval system, single and dual cycle times.

\section{INTRODUCTION}

An automated Storage Retrieval system (AS/RS) is an important technology in modern manufacturing and in the logistics industry. It refers to a computerized robotic system that automates operations such as unloading, sorting, put-away, storage, order-picking, staging and loading. Systems typically consist of four main components: the storage rack, the input/output system, the storage and retrieval ( $\mathrm{S} / \mathrm{R})$ equipment, and the computer management system or the control system.

There are various important categories of automated storage/retrieval systems which can be classified according to the bins arrangement and the number of S/R machines used in the system. We can classify as follows [1]:

1) Unit load AS/RS: it is composed of one aisle including a rack on each side. Racks are themselves composed of bins. The aisle is served by a $\mathrm{S} / \mathrm{R}$ machine. It is the basic and the most studied form.

2) Miniload AS/RS: Used to store/retrieve small parts and tools that can be stored in a storage bin or drawer.

Manuscript received October 9, 2012; revised May 5, 2013.

A. H. Guezzen and Z. Sari are with Manufacturing Engineering Laboratory of Tlemcen (MELT), University of Tlemcen, Faculty of Technology, Algeria (e-mail: amine.guezzen@yahoo.fr, z_sari@mail.univ-tlemcen.dz).

P. Castagna and O. Cardin are with Institut de Recherche en Communications et Cybernétique de Nantes (IRCCyN), IUT of Nantes France(e-mail: pierre.castagna@univ-nantes.fr).
3) Man-On-Board AS/RS: Used for in-aisle picking; operator picks from shelves, bins, or drawers within the storage structure

4) flow-rack systems: A flow-rack AS/RS includes a rack which consists of sloping bins, where items loaded by a storage machine at one end of the rack on the store face travel along sloping wheels or rollers to the other end of the rack on the pick face, to be retrieved by a retrieval machine. [2]

5) Multi aisles AS/RS: This type of AS/RS comprises several aisles, all served by only one $\mathrm{S} / \mathrm{R}$ machine. This allows the storage of a big number of products.

6) Carousel systems: in this kind of systems the racks rotate on a circular track, and the picking machine carries out storage and retrieval activities at a fixed position.

7) Mobil racks AS/RS: a M-AS/RS is a picker-to-stock retrieval model which is a variation of the multi aisles AS/RS. This mobile storage system is composed of racks moving laterally on rails so that one can open an aisle between any two adjacent racks.

Many issues related to the efficiency of the AS/RS have been studied in the literature, A study for the expected travel-time (average travel Time) model in AS/RS was firstly made by Husman et al. (1976) [3]. Schwarz el al. (1978) [4] and Graves et al. (1977) [5] assuming that the racks are square in time (i.e., horizontal maximum travel time is equal to vertical maximum travel time). Next, Bozer and White (1984) [6] presented an analytical models for calculation of Single and dual command cycle for non square-in-time racks, The AS/RS considered are of a unit-load type.

Studies of multi aisle AS/RS served by the single $\mathrm{S} / \mathrm{R}$ machine have been presented by different authors, Han and Al (1997) [7] developed a mathematical expression estimating the dual cycle time, under the rule nearest neighbor. Hwang and Ko (1988) [8] proposed a mathematical expression for multi aisle AS/RS. In this work, each rack is considered as a continuous face and for each rack an analytical expression of the cycle time is developed.

In (2004) [9], Tone Lerher and al considered acceleration and deceleration of the $S / R$ machine and they proposed an analytical model of the cycle time for multi aisle AS/RS. Ghomri and al (2008)[10], [11] used a continuous approximation of the rack of storage in order to develop a mathematical expression that allows the calculation of the time of single and double cycle of multi aisle AS/RS .

\section{SYSTEM STRUCTURE AND CONFIGURATION}

As illustrated in Fig. 1, in this system, there is only one aisle needed to handle goods, after separating two adjacent rows of equipment, an aisle is formed. The storage/retrieval 
machine (S/R-m) then enters the aisle to pick and place the item on a storage rack. Movement velocity is controlled by the frequency conversion modulation, so the movement is very steady. It's capable of simultaneously moving both vertically and horizontally (the Tchebychev travel).

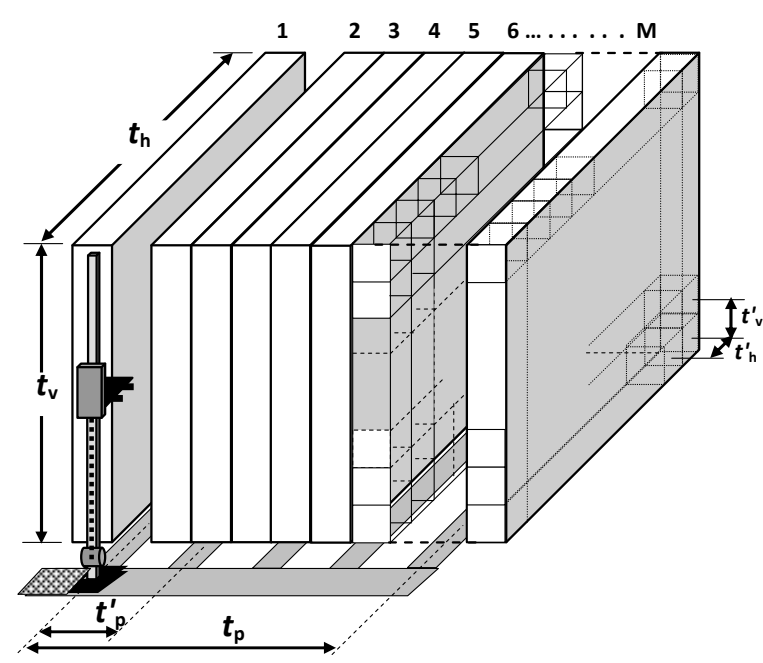

Fig. 1. Mobil racks automated Storage Retrieval system

\section{A. Notations}

The following notations are made throughout this paper:

$M:$ The number of racks in a M- AS/RS

$N_{L}$ : The number of bins per line

$N_{H}$ : The number of bins per column

$N$ : The entire number of bins

$t^{\prime}{ }_{h}$ :The horizontal travelling time from a bin to the next one

$t^{\prime}{ }_{v}:$ The vertical travelling time from a bin to the next one

$t_{p}$, The travelling time from an aisle to the nearest one in a M- AS/RS

$t_{h}$ :Time necessary to traverse the length of a rack or the length of an aisle

$t_{v}$ :Time necessary to traverse the height of a rack

$t_{P}$ :Time necessary to traverse the principle aisle of the MAS/RS

$t_{r}$ :Time necessary for the opening of an aisle; (slipping of racks)

$\overline{E(S C)}$ : Mean single cycle time

\section{Discrete Models OF MobILE RACK AS/RS}

As presented in Fig. 2, the single cycle time of the $S / R$ machine is the time needed to go from the input/output station to the storage (retrieval) cell, plus the time needed to return from this cell to the input/output station [12].

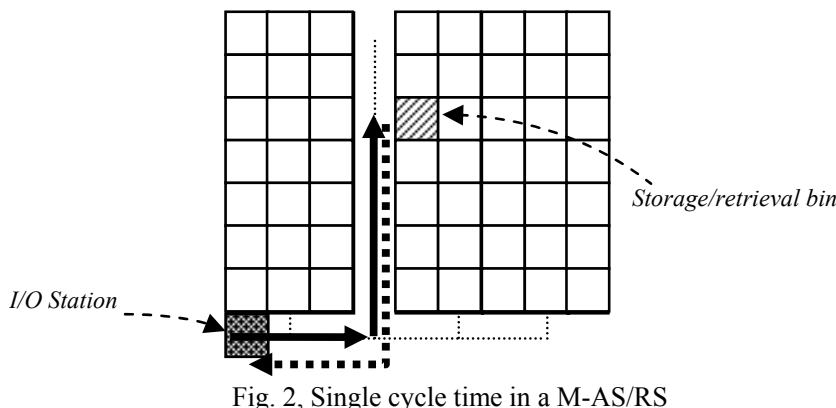

Horizontal displacement necessary to reach the rack with the coordinates $(i, j)$ which is in the $k^{t h}$ aisle is given by:

$$
t^{\prime}{ }_{h \cdot i}+\max \left(t_{r} ; t_{p \cdot}^{\prime}(k-1)\right)
$$

The vertical displacement needed to reach this same cell is:

$$
t^{\prime}{ }_{v} \cdot(j-1)
$$

Thanks to technology used in the storage retrieval machines and the Tchebychev travel, the total time that $\mathrm{S} / \mathrm{R}$ machine puts to reach this rack is the maximum between horizontal and vertical displacement.

$$
\operatorname{Max}\left[t^{\prime}{ }_{h \cdot i}+\max \left(t_{r} ; t_{p \cdot} \cdot(k-1)\right) ; t^{\prime} \cdot(j-1)\right]
$$

Total time that the $\mathrm{S} / \mathrm{R}$ machine needs to return to the input/output point does not depend on " $t_{r}$ " is given by the expression:

$$
\operatorname{Max}\left[t^{\prime}{ }_{h \cdot i} i+t^{\prime}{ }_{p \cdot} \cdot(k-1) ; t^{\prime} \cdot(j-1)\right]
$$

So, the average cycle time for all the cells is given by the following expression:

$$
\begin{aligned}
\overline{E(S C)}= & \frac{2}{N} \sum_{k=1}^{M / 2} \sum_{i=1}^{N_{L}} \sum_{j=1}^{N_{H}}\left(\max \left[t^{\prime}{ }_{h} . i+\max \left(t r, t^{\prime}{ }_{p} .(k-1)\right), t^{\prime} v \cdot(j-1)\right]\right. \\
& \left.+\max \left[t^{\prime}{ }_{h} . i+t^{\prime}{ }_{p} .(k-1), t^{\prime}{ }_{v} .(j-1)\right]\right)
\end{aligned}
$$

\section{Continuous Models of Mobile Rack AS/RS}

The employs of a continuous approximation of the storage racks allows us to develop mathematical expressions for the calculation of the travel time of the M-AS/RS, in this section we present two possible cases depending on the value of time sliding racks [13], [14]:

$$
1^{\text {st }} \text { case }: t_{r}>t_{p}
$$

In this case, the average time for single cycle is given by expression (6) whatever the value taken $t_{p}$, th and $t_{v}$.

$$
\begin{aligned}
& E(S C)=t_{h}+t_{r}+\frac{1}{2} t_{p}+\frac{\max \left(0, t_{v}-t_{r}\right)^{3}}{6 t_{h} t_{v}}+\frac{\min \left(0, t_{h}+t_{r}-t_{v}\right)^{3}}{6 t_{h} t_{v}}+\frac{t_{v}{ }^{3}}{24 t_{p} t_{h}} \\
& +\frac{\left(t_{v}-t_{p}-t_{h}\right)^{3} \max \left(0, t_{v}-t_{p}-t_{h}\right)-\left(t_{v}-t_{p}\right)^{3} \max \left(0, t_{v}-t_{p}\right)-\left(t_{v}-t_{h}\right)^{3} \max \left(0, t_{v}-t_{h}\right)}{24 t_{p} t_{h} t_{v}}
\end{aligned}
$$

$2^{\text {nd }}$ case $: t_{r}<=t_{p}$

Average cycle time necessary for the displacement of $S / R$ machine from the I/O Station to the storage racks is given by the expressions $E\left(S C_{l}\right)$ according to the variation of $\mathrm{t}_{\mathrm{p}}, t_{p}, t_{v}$, $t_{h}, t_{r}$ values:

$$
\begin{aligned}
& -\quad 0<t_{v}<=t_{r} \\
& E\left(S C_{1}\right)=\frac{t_{p}}{2}+\frac{t_{h}}{2}+\frac{t_{r}{ }^{2}}{2 t_{p}} \\
& -\quad t_{r}<t_{v}<=t_{p} \\
& E\left(S C_{1}\right)=\frac{t_{p}}{2}+\frac{t_{h}}{2}+\frac{t_{r}{ }^{2}}{2 t_{p}}+\frac{8 t_{v} t_{r}{ }^{3}-6 t_{r}{ }^{2} t_{v}{ }^{2}+t_{v}{ }^{4}-3 t_{r}{ }^{4}}{24 t_{p} t_{h} t_{v}} \\
& -\quad t_{p}<t_{v}<=t_{h}+t_{r} \\
& E\left(S C_{1}\right)=\frac{t_{p}}{2}+\frac{t_{h}}{2}+\frac{t_{r}{ }^{2}}{2 t_{p}}-\frac{\left(t_{p}-t_{h}\right)^{4}+\left(t_{v}-t_{r}\right)^{4}-2 t_{v}{ }^{4}-4 t_{v} t_{r}{ }^{3}+2 t_{r}{ }^{4}}{24 t_{p} t_{h} t_{v}} \\
& -\quad t_{h}+t_{r}<t_{v}<=t_{p}+t_{h}
\end{aligned}
$$




$$
\begin{aligned}
& E\left(S C_{1}\right)=\frac{t_{p}}{2}+\frac{t_{h}}{2}-\frac{\left(t_{v}-t_{h}\right)^{4}+\left(t_{v}-t_{p}\right)^{4}-t_{v}{ }^{4}-6 t_{h}{ }^{2} t_{r}{ }^{2}+8 t_{h} t_{r}{ }^{3}}{24 t_{p} t_{h} t_{v}} \\
& -\quad t_{p}+t_{h}<t_{v} \\
& E\left(S C_{1}\right)=\frac{t_{v}}{2}+\frac{3 t_{h} t_{r}{ }^{2}+3 t_{p}{ }^{2} t_{h}+4 t_{r}{ }^{3}+3 t_{p} t_{h}{ }^{2}+2 t_{p}{ }^{3}}{12 t_{p} t_{v}}
\end{aligned}
$$

The return of $\mathrm{S} / \mathrm{R}$ machine to the input output station does not depend on the $t_{\mathrm{r}}$ value and it is given by the expression $\mathrm{E}\left(\mathrm{SC}_{2}\right)$ :

$$
\begin{aligned}
& E\left(S C_{2}\right)=\frac{1}{2} t_{p}+\frac{1}{2} t_{h}+\frac{t_{v}{ }^{3}}{24 t_{p} t_{h}} \\
& +\frac{\left(t_{v}-t_{p}-t_{h}\right)^{3} \max \left(0, t_{v}-t_{p}-t_{h}\right)-\left(t_{v}-t_{p}\right)^{3} \max \left(0, t_{v}-t_{p}\right)-\left(t_{v}-t_{h}\right)^{3} \max \left(0, t_{v}-t_{h}\right)}{24 t_{v} t_{p}}
\end{aligned}
$$

Consequently, the sum of the two expressions $\mathrm{E}\left(\mathrm{SC}_{1}\right)$ and $\mathrm{E}\left(\mathrm{SC}_{2}\right)$ gives the average time in the single command for a $\mathrm{M}-\mathrm{AS} / \mathrm{RS}$ in the case where $t_{r}<=t_{p}$.

\section{V.Simulation AND VALIDATION OF MOBILE RACK AS/RS}

Simulation with events discrete allows the reproduction of the behavior of complexes systems not easily controllable and possibly subjected to random phenomena. The real system behavior with all its components (physics, informational, decisional) is thus replaced by a virtual model having a similar behavior. The utilized simulator is a computer program making it possible to carry out experiments in order to apprehend the behavior of the real system, to evaluate its performances and to help with the anticipation of possible drifts. The aim of our simulation is to validate the analytical expressions suggested in sections 3 and 4 . For that, it was necessary a model making it possible for us to simulate the behavior of system having unspecified sizes. More than a simple simulator, we needed a tool allowing the automatic generation of M-AS/RS model.

To simulate the studied mobile storage system we chose to use the Arena software of Rockwell Software. The system ARENA is an integrated support of modeling, it making possible to build detailed models for a wide range of possible applications.

ARENA also integrates all the functions related to simulation, such as: animation, data analysis of input, the checking of the model and analysis of the results in only one environment of modeling [15]. Lastly, and especially, it integrates a layer VBA (Visual BASIC for Application) which we largely used for our simulation.

To evaluate the continuous model for its accuracy, we

\begin{tabular}{|c|c|c|c|c|c|c|c|c|c|c|c|c|c|}
\hline Configurations & 1 & 2 & 3 & 4 & 5 & 6 & 7 & 8 & 9 & 10 & 11 & 12 & 13 \\
\hline nbr of bins $\mathrm{N}$ & 400 & 800 & 800 & 800 & 1000 & 1000 & 1000 & 2000 & 2000 & 2000 & 4000 & 4000 & 4000 \\
\hline Bins per line $\left(\mathrm{N}_{\mathrm{L}}\right)$ & 10 & 5 & 5 & 5 & 10 & 10 & 10 & 10 & 10 & 10 & 10 & 10 & 10 \\
\hline $\begin{array}{l}\text { Bins per column } \\
\mathrm{N}_{\mathrm{H}}\end{array}$ & 5 & 10 & 10 & 10 & 10 & 10 & 10 & 10 & 10 & 10 & 20 & 20 & 20 \\
\hline Nbr of racks (M) & 8 & 16 & 16 & 16 & 10 & 10 & 10 & 20 & 20 & 20 & 20 & 20 & 20 \\
\hline Nbr of aisle $((\mathrm{M} / 2)$ & 4 & 8 & 8 & 8 & 5 & 5 & 5 & 10 & 10 & 10 & 10 & 10 & 10 \\
\hline Sliding time $\left(\mathrm{t}_{\mathrm{r}}\right)$ & 200 & 20 & 200 & 500 & 40 & 100 & 250 & 40 & 200 & 500 & 40 & 200 & 500 \\
\hline $\mathrm{t}_{\mathrm{h}}^{\prime}$ & 50 & 50 & 50 & 50 & 50 & 50 & 50 & 50 & 50 & 50 & 50 & 50 & 50 \\
\hline$t_{p}^{\prime}$ & 50 & 50 & 50 & 50 & 50 & 50 & 50 & 50 & 50 & 50 & 50 & 50 & 50 \\
\hline $\mathrm{T}_{\mathrm{P}}$ & 150 & 350 & 350 & 350 & 200 & 200 & 200 & 450 & 450 & 450 & 450 & 450 & 450 \\
\hline Simulation & 791,96 & 716,34 & 746,67 & 968,30 & 804,01 & 815,55 & 899,78 & 1026,58 & 1057,68 & 1259,94 & 1250,62 & 1267,1 & 1406,52 \\
\hline $\begin{array}{l}\text { Discret } \\
\text { model(ESC) }\end{array}$ & 828,75 & 729,75 & 766,25 & 1014,37 & 818,12 & 833,8 & 936,5 & 1035,56 & 1072,25 & 1291,05 & 1267,55 & 1287,5 & 1438,12 \\
\hline
\end{tabular}
compare the results obtained from the model with those from

\begin{tabular}{|c|c|c|c|c|c|c|c|c|c|c|c|c|}
\hline Configurations & 14 & 15 & 16 & 17 & 18 & 19 & 20 & 21 & 22 & 23 & 24 & 25 \\
\hline nbr of bins $\mathrm{N}$ & 4000 & 4000 & 4000 & 4000 & 4000 & 4000 & 10000 & 10000 & 10000 & 10000 & 10000 & 10000 \\
\hline Bins per line $\left(\mathrm{N}_{\mathrm{L}}\right)$ & 20 & 20 & 20 & 10 & 10 & 10 & 10 & 10 & 10 & 50 & 50 & 50 \\
\hline Nbr of racks (M) & 20 & 20 & 20 & 40 & 40 & 40 & 20 & 20 & 20 & 20 & 20 & 20 \\
\hline Nbr of aisle $((\mathrm{M} / 2)$ & 10 & 10 & 10 & 20 & 20 & 20 & 10 & 10 & 10 & 10 & 10 & 10 \\
\hline$t_{h}^{\prime}$ & 50 & 50 & 50 & 50 & 50 & 50 & 50 & 50 & 50 & 50 & 50 & 50 \\
\hline$t_{p}^{\prime}$ & 50 & 50 & 50 & 50 & 50 & 50 & 50 & 50 & 50 & 50 & 50 & 50 \\
\hline $\mathrm{T}_{\mathrm{P}}$ & 450 & 450 & 450 & 950 & 950 & 950 & 450 & 450 & 450 & 450 & 450 & 450 \\
\hline Simulation & $\begin{array}{c}1514,4 \\
6\end{array}$ & 1549,08 & 1753,16 & 1512,78 & 1631,32 & 2109,3 & 2566,62 & $\begin{array}{c}2572,9 \\
2\end{array}$ & 2627,02 & 3008,18 & 3044,72 & 3249,56 \\
\hline $\begin{array}{l}\text { Discret } \\
\text { model(ESC) }\end{array}$ & $\begin{array}{c}1519,7 \\
8\end{array}$ & 1561,13 & 1783,25 & 1517,78 & 1645,75 & 2133,25 & 2577,02 & 2585 & 2645,25 & 3010,31 & 3054,45 & 3278,3 \\
\hline
\end{tabular}
the computer simulations for 25 different configurations as illustrated in Table I.

TABLE I: SIMULATION RESULTS FOR 25 DIFFERENT CONFIGURATIONS 
Table I gives the simulation results, the continuous and the discrete travel time for 25 different configurations. And from this table, it can be observed that the maximum ( $\%$ deviation) is less than $5 \%$, and this shows that the continuous model and the simulation performs quite well comparing with the exact model ( discrete model).

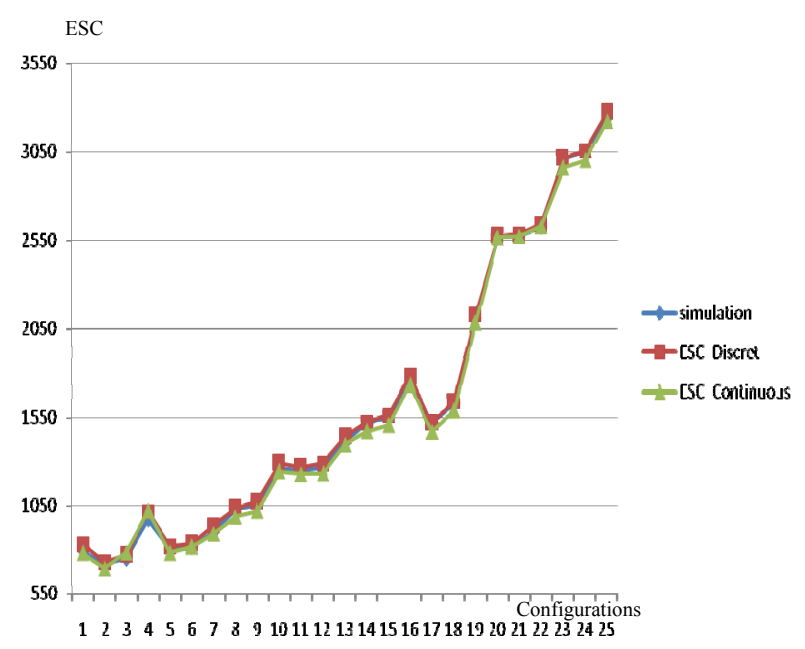

Fig. 3. Comparison between results given by the continuous, discrete expression and simulation

\section{CONCLUSION}

In this paper, we presented two analytical models allowing envisaging the performances of a mobile racks automated storage/retrieval system. Then, we had the results of simulation given by an ARENA model with several dimensions and configurations. The comparison between the analytical results and the results of simulation shows a good behavior of the developed models. These results are of great importance for a good comprehension of these kinds of systems, choice of dimensions and the management of this type of installation.

In the continuation, we propose to study other structures, comprising for example a second $\mathrm{S} / \mathrm{R}$ machine located on the back of the system.

\section{REFERENCES}

[1] M. G. Kay “Lecture notes for Production System Design,” Spring 2009 NC 27695-7906.

[2] Z. Sari, C. Saygin, and N. Ghouali, "Travel-time models for flow-rack automated storage and retrieval systems," Int J Adv Manuf Technol (2005) 25, pp. 979-987.

[3] H. W. Hausman, B. L. Schwarz, and C. S. Graves, "Optimal storage assignment in automatic warehousing systems," Manage Sci, vol. 22 , no. 6, pp. 629-638, 1976.

[4] L. B. Schwarz, S. C. Graves, and W. H. Hausman, "Scheduling policies for automatic warehousing systems: simulation results," AIIE Trans, vol. 10, no.1, pp. 260-270, 1978.

[5] S. C. Graves, W. H. Hausman, L. B. Schwarz, "Storage retrieval interleaving in automatic warehousing systems," Manage Sci, vol. 23, no. 7, pp. 935-945, 1977.

[6] Y. A. Bozer and J. A. White, "Travel time for automated storage/retrieval systems," IIE Transactions, (1984), vol.16, no. 4, pp. 329-338.
[7] M. H. Han, L. F. McGinnis, J. S. Shieh, and J. A. White, "On sequencing retrievals in an automated storage/retrieval system," IIE Transactions, vol. 19, pp. 56-66, 1987.

[8] H. Hwang and C. S. Ko, "A study on multi-aisle system served by a single storage/retrieval machine," Int J Prod Res, vol. 26, no. 11, pp. 1727-1737, 1988.

[9] T. Lerher, M. Sraml, J. Kramberger, I. Potrc, M. Borovinsek, and B. Zmazek, "Analytical travel time models for multi aisle automated storage and retrieval systems," Int J Adv Manuf Technol.

[10] L. Ghomri, Z. Sari, A. H. Guezzen, and T. Sari, "Expressions Analytiques Du Temps De Cycle Pour Les As/Rs Multi Allées," la 7èmes Conférence Internationale de Modélisation et Simulation MOSIM'08 - Paris- France.

[11] L. Ghomri, Z. Sari, A. H. Guezzen, and T. SARI, "Continuous models for single and dual cycle times of a multi aisle automated storage and retrieval systems," in Proc. of INCOM'09, pp. 1065-1070, 3-5 Juin 2009, Moscou Russie.

[12] Z. Sari, "Expressions analytiques discrètes de simple et double cycle d'un AS/RS à rack glissant," Rapport interne, LAT, Université Abou-Bekr Belkaïd, Tlemcen, Algérie, 1998.

[13] A. H. Guezzen, Z. Sari, and L. Ghomri, "A study on Mobil racks automated storage and retrieval system (M-AS/RS)," DOI: 10.1109/ CCCA.2011.6031446.

[14] A. H. Guezzen, Z. Sari, and L. Ghomri, "Continuous model for single cycle times of a mobile racks automated storage and retrieval system," MISC'11, 2011.

[15] D. Kelton, R. P. Sadowski, and Deborah A. Sadowski, Simulation with Arena, WCB McGraw-Hill, Boston, 1998.

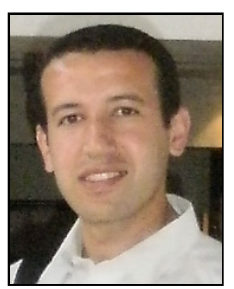

M. Amine Hakim Guezzen is an assistant professor and researcher at University of Tlemcen (UABT), Faculty of Technology, Algeria; he is member of Manufacturing Engineering Laboratory of Tlemcen (MELT). He obtained his Engineer degree in control from the University of Tlemcen, in 2002; his Magister degree in Manufacturing Engineering from the same university in 2006; and now, he is preparing his doctoral thesis.

His main domain of interest concerns the industrial maintenance, Design, Modeling, Simulation and Control of Automated Storage and Retrieval System; he made several investigations on mobile racks AS/RS systems and multi aisle AS/RS systems.

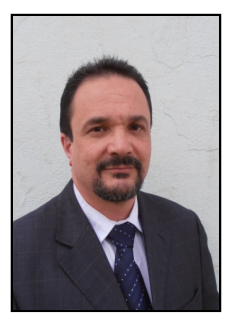

Zaki Sari is currently a manufacturing engineering professor at Aboubekr Belkaid University of Tlemcen (UABT), Algeria; he is the Director of Manufacturing Engineering Laboratory of Tlemcen (MELT), and the head of the National Curriculum of Manufacturing Engineering. He obtained his Engineer degree in electrical engineering from the National Institute of Electrical Engineering, Boumerdes, Algeria in 1987; his Magister degree in power engineering from the National Polytechnic School of Algiers, Algeria in 1990; and his Doctorate degree in manufacturing engineering from Tlemcen University in 2003. He obtained also a certificate in system engineering management from University of Missouri Rolla, USA, in 2003.

His main domain of interest concerns the Design, Modeling, Optimization, Simulation and Control of Automated Storage and Retrieval System, he made several investigations on non conventional AS/RS systems like flow rack systems but employed for different uses than the ones designed for. Other domains that he is interested in include Flexible Manufacturing Systems, Scheduling, Supply Chain Management...

He was the instigator of several Bs and Ms Curricula in manufacturing and industrial Engineering. 